\title{
Совершенствование технологии возделывания томата и конструкции весенних теплиц для получения экологически безопасной продукции
}

\author{
Improving tomato cultivation technology and spring greenhouse construction to produce \\ ecological safely products
}

\author{
Чернова Т.В., Огнев В.В., Авдеенко С.С., Габибова Е.Н., \\ Корсунов Е.И.
}

\section{Аннотация}

В России интенсивно развивается овощеводство защищенного грунта. Наблюдается рост площадей зимних и весенних теплиц. Площадь весенних теплиц достигла 20 тыс. га. Весенние теплицы стали основным типом культивационных сооружений при производстве ранних томатов. Весенние теплицы чаще используются в мелких хозяйствах. Конструкции теплиц и применяемые технологии сильно различаются и не позволяют использовать промышленные технологии производства томата. В мелких тепличных хозяйствах сложно получать экологически безопасную продукцию. Цель исследований - разработка приемов возделывания новых гибридов томата в весенних теплицах и совершенствование конструкций теплиц для получения экологически безопасной продукции. Исследования проведены в 2016-2019 годах в селекционно-семеноводческом центре «Ростовский» Агрохолдинга «Поиск», расположенном в Октябрьском районе Ростовской области. Климат зоны жаркий, засушливый, с продолжительным безморозным периодом. Погодные условия в годы проведения исследований отличались резкими перепадами температуры в весенний период, высокими температурами при острой нехватке осадков и низкой влажностью воздуха в летний период. Почвы в опытах - чернозем обыкновенный с добавлением рыхлящих материалов. Содержание доступных элементов питания - высокое. Опыты закладывали в весенних теплицах ангарного типа с поликарбонатным светопрозрачным покрытием без обогрева. Теплицы оснащены системами капельного орошения с фертигацией. Объектом исследований служили конструкции теплиц, отдельные элементы технологии возделывания и гибриды томата. В результате исследований установлено, что для получения экологически безопасной продукции томата в весенних теплицах необходима их модернизация с увеличением внутреннего объема за счет увеличения высоты по коньку до 4,5 м. Теплицы должны быть оснащены вытяжной вентиляцией, противомоскитными сетками на вентиляции, тамбуром с дезинфекционным барьером на входе. В технологии выращивания томата необходимо включить использование промежуточных злаковых культур с заделкой на сидераты и комплексных безбалластных водорастворимых удобрений в корневых и листовых подкормках. Подвязка и формировка растений томата должна учитывать сортовые особенности. Для защиты от вредных организмов необходимо использовать сочетание комплексной устойчивости новых гибридов томата с применением биопрепаратов, карантинных, профилактических и агротехнических мероприятий. Модернизация весенних теплиц и внедрение предложенных элементов технологии выращивания томата позволяют обеспечить гарантированное получение экологически безопасной продукции.

Ключевые слова: весенние теплицы, модернизация, конструкции, томат, технология, удобрение, защита растений, гибрид.

Для цитирования: Совершенствование технологии возделывания томата и конструкции весенних теплиц для получения экологически безопасной продукции / Т.В. Чернова, В.В. Огнев, С.С. Авдеенко, Е.Н. Габибова, Е.И. Корсунов // Картофель и овощи. 2020. №5. C. 11-16. https://doi.org/10.25630/PAV.2020.10.27.002

\author{
Chernova T.V., Ognev V.V., Avdeenko S.S., Gabibova E.N., \\ Korsunov E.I.
}

\section{Abstract}

In Russia the vegetable production of protected soil is developing intensively. There is an increase in the area of winter and spring greenhouses. The area of spring greenhouses has reached 20 thousand ha. Spring greenhouses have become the main type of cultivation structures in the production of early tomatoes. Spring greenhouses are more often used in small farms. The constructions of greenhouses and the technologies used vary greatly and do not allow the use of industrial technologies for the production of tomatoes. In small greenhouse farms it is difficult to obtain environmentally safe products. The main purpose of the research is to develop technology for cultivating new tomato hybrids in spring greenhouses and to improve greenhouse constructions to produce ecological safely products. The research was carried out in 2016-2019. at the Rostovsky breeding centre of Poisk Agro holding, located in the October district of Rostov region. The climate of the zone is hot, arid, with a long frost-free period. Weather conditions during the study years were characterized by sharp temperature changes in the spring, high temperatures with severe lack of precipitation and low humidity in the summer. Soils in experiments - ordinary chernozem with the addition of loose materials. The content of available batteries is high. Experiments were laid in spring greenhouses hangar type with polycarbonate translucent coating without heating. The greenhouses are equipped with drip irrigation systems with fertigation. The object of research was the construction of greenhouses, individual elements of the technology of cultivation and hybrids of tomato. As a result of research, it has been established that in order to obtain environmentally safe products of tomatoes in spring greenhouses, they need to be modernized with an increase in internal volume by increasing the height of the skate to $4.5 \mathrm{~m}$. Greenhouses should be equipped with exhaust ventilation, mosquito nets on ventilation, a tambour with a disinfectant barrier at the entrance. In tomato growing technology it is necessary to include the use of intermediate cereal crops with rooting on siderates and complex ballast-free water-soluble fertilizers in root and leaf fertilization. The garter and formation of tomato plants should take into account varietal features. To protect against harmful organisms, it is necessary to use a combination of complex stability of new hybrids of tomato with the use of biologics, quarantine, preventive and agrotechnical measures. Modernization of spring greenhouses and the introduction of the proposed elements of tomato growing technology make it possible to ensure the guaranteed receipt of ecological safely products

Key words: spring greenhouses, modernize, constructions, tomato, technology, fertilizer, plant protection, hybrid.

For citing: Improving tomato cultivation technology and spring greenhouse construction to produce ecological safely products. T.V. Chernova, V.V. Ognev, S.S. Avdeenko, E.N. Gabibova, E.I. Korsunov. Potato and vegetables. 2020. No5. Pp. 11-16. https://doi.org/10.25630/ PAV.2020.10.27.002 (In Russ.). 
P азвитию защищенного грунта в России придается первостепенное значение. Начиная с 2013 года идет интенсивное возрождение отрасли, строятся тепличные комбинаты под стеклом, проводится реконструкция сохранившихся, осваиваются новые технологии и совершенствуется сортимент [1]. Однако только за счет зимних теплиц невозможно осуществить самообеспечение населения овощами во внесезонный период. Для этого активно используют более простые сооружения и утепленный грунт [2].

Сегодня основным типом культивационных сооружений в России остаются весенние теплицы. В отличие от зимних теплиц, площадь которых приближается к 3 тыс. га, их площадь превышает 20 тыс. га [3]. В весенних теплицах выращивают значительные объемы ранней продукции. Основные культуры здесь - томат и огурец. И если в среднем по стране доля томата не превышает 30-35\%, то на юге России он занимает более 70\% посевных площадей [4, 5]. Основными регионами юга России, где развито производство томата в весенних теплицах, считаются Ростовская и Волгоградская области, республики Северного Кавказа [4, 6]. Производство это сильно диверсифицировано и отличается большим разнообразием конструкций и светопрозрачных покрытий, спецификой почвогрунтов, особенностями микроклимата и его регулирования. Как правило, весенние теплицы используют мелкие товарные хозяйства и значительно реже крупные комбинаты [7]. Для мелких хозяйств характерно использование самых разных технологий и сортимента, часто не имеющих научного обоснования и сопровождения [8]. Созданием сортимента томата для весенних теплиц в России занимаются практически исключительно частные селекционно-семеноводческие компании, они же вынуждены заниматься разработкой и усовершенствованием приемов его возделывания [9]. Особые проблемы при выращивании в весенних теплицах возникают при получении экологически безопасной продукции, что требует освоения специальных приемов возделывания, сортимента с комплексной устойчивостью к патогенам и неблагоприятным факторам среды, новых агрохимикатов и технических средств [10]. Наблюдается явный дефицит научных рекомендаций по возделыванию современных гибридов томата в ве- сенних теплицах по биологизированным технологиям, требующий устранения в ближайшие сроки.

В связи с этим основной целью исследований была разработка приемов возделывания новых гибридов томата в весенних теплицах и совершенствование конструкций теплиц, применяемых в них технологий для получения экологически безопасной продукции.

Для достижения поставленной цели было предусмотрено решение следующих задач: 1. Разработать и апробировать конструктивные изменения теплиц, способствующие улучшению микроклимата и позволяющие получать экологически безопасную продукцию; 2. Изучить возможность использования биологизированной технологии возделывания томата на основе освоения гибридов с комплексной устойчивостью, агроприемов с минимальным использованием химических средств защиты растений, балластных удобрений и иных агрохимикатов.

Условия, материалы и методы исследований

Исследования проводили в 20162019 годах в селекционно-семеноводческом центре «Ростовский» Агрохолдинга «Поиск», расположенном в слободе Красюковской Октябрьского района Ростовской области. Материалом для исследований служили гибриды томата собственной селекции, рекомендованные к использованию в регионе, отдельные разработки по изменению конструкций теплиц и технологий возделывания томата с использованием элементов биологизации. Для проведения исследований использовали необогреваемые весенние теплицы арочного типа собственной конструкции с поликарбонатным покрытием. Климат зоны жаркий, засушливый, с продолжительным безморозным периодом. Погодные условия в годы проведения исследований отличались резкими перепадами температуры в весенний период, высокими температурами при острой нехватке осадков и низкой влажностью воздуха в летний период. Почвы в опытах представлены черноземом обыкновенным с улучшенным механическим составом за счет внесения рыхлящих материалов. Содержание гумуса 5,6\%. Содержание доступных элементов питания высокое, рН почвенного раствора 7,8. Для орошения и удобрения использована система капельного полива с фертигацией. Рассаду томата выращивали с забе- гом 55 дней в разводочной теплице с пикировкой в пластиковые контейнеры. Рассаду высаживали в последней декаде апреля по схеме $70 \times 30$ см с подвязкой к шпалере. Формировали растения с учетом сортовых особенностей по разработанным системам. Уход включал формировку растений, поливы с внесением удобрений, листовые подкормки, защиту от вредных организмов. Регулирование микроклимата осуществлялось с использованием орошения и вентиляции. Уборку урожая проводили регулярно по мере созревания плодов. Учеты и наблюдения за растениями вели по принятым методикам [11,12].

\section{Результаты исследований}

Конструктивные особенности теплиц существенно влияют на величину урожайности гибридов томата, качество плодов, фитосанитарное состояние в самих теплицах. По всем показателям преимущество имеют теплицы высотой более 4,5 м по коньку с верхней вытяжной вентиляцией. При дополнительном оснащении теплиц тамбурами с дезинфекционными барьерами и установкой противомоскитной сетки на вентиляционные системы заметно снижается повреждение растений томата тепличной белокрылкой (табл.).

Особенно важным представляется для юга России устройство вытяжной вентиляции в верхней части кровли для выхода горячего воздуха. Это, наряду с увеличением высоты кровли и внутреннего объема теплицы, существенно улучшает микроклимат. Прохладный приземный слой воздуха проходя через форточки в нижней части светопрозрачного покрытия охлаждает растения и, постепенно нагреваясь, выходит через вытяжную вентиляцию в кровле. По мере роста растений эффект охлаждения усиливается за счет увлажнения воздуха в результате транспирации растений. В жаркий летний период разница в температуре внутри теплиц с вытяжной вентиляцией и без нее достигает $10{ }^{\circ} \mathrm{C}$ и более. Меньшие перепады суточных значений температуры и влажности способствуют более высокой продуктивности растений. Оснащение теплиц противомоскитной сеткой и тамбурами с дезинфицирующим барьером сокращает потребность в проведении защитных мероприятий от многих насекомых. Наибольший эффект достигается в контроле численности таких вредителей как белокрылка, совки и минирующие моли. В меньшей степени это касается таких вре- 


\begin{tabular}{|c|c|c|c|c|}
\hline Конструкция теплицы & $\begin{array}{c}\text { Общая, } \\
\text { урожайность, кг/м² }\end{array}$ & Товарность, \% & $\begin{array}{l}\text { Средняя масса } \\
\text { плода, г }\end{array}$ & $\begin{array}{l}\text { Количество особей } \\
\text { белокрылки, шт/лист* }\end{array}$ \\
\hline $\begin{array}{l}\text { Теплица высотой 2,5 м, без вытяжной вентиляции, } \\
\text { противомоскитной сетки и тамбура (контроль) }\end{array}$ & 10,4 & 96,4 & 120,2 & 10,8 \\
\hline $\begin{array}{l}\text { Теплица высотой } 4,5 \text { м, с вытяжной вентиляцией, } \\
\text { противомоскитной сеткой и тамбуром }\end{array}$ & 14,6 & 98,2 & 140,8 & 1,2 \\
\hline $\begin{array}{l}\text { Теплица высотой } 4,5 \text { м, без вытяжной вентиляции, } \\
\text { с противомоскитной сеткой и тамбуром }\end{array}$ & 12,8 & 98,0 & 140,0 & 1,2 \\
\hline $\begin{array}{l}\text { Теплица высотой } 2,5 \text { м, без вытяжной вентиляции, } \\
\text { с противомоскитной сеткой и тамбуром }\end{array}$ & 10,8 & 96,6 & 120,6 & 1,6 \\
\hline $\mathrm{HCP}_{05}$ & 0,38 & - & 4,5 & 0,4 \\
\hline
\end{tabular}

дителей как трипсы, клещи и тли. Здесь большее значение приобретают меры по дезинфекции теплиц и внутрихозяйственные карантинные мероприятия.

В большинстве хозяйств в весенних теплицах растения выращивают на естественных грунтах. Несменяемость грунтов и монокультура томата приводят к распространению разнообразной почвенной инфекции и инфекции, сохраняющейся на растительных остатках. Для изменения этой негативной тенденции необходимо поддерживать строгий санитарный режим в сооружениях. После окончания оборота, растения обеззараживают и только затем удаляют все растительные остатки. Перед оборотом теплицу, тару, инвентарь и спецодежду также подвергают обеззараживанию. Почвогрунты обеззаразить значительно сложнее. Здесь важно подавить вредную микробиоту. Для этих целей наиболее рационально использовать промежуточные культуры, особенно если нет плодосмена. Наиболее опасные для томата почвенные патогены - грибы из рода фузарий. Они являются обычной почвенной микрофлорой, но способны переходить на паразитарный тип питания и вызывать трахеомикозное увядание. В качестве промежуточных испытано много культурных растений. Наибольший эффект достигнут при выращивании ржи, тритикале и овса. На корнях этих растений разрастаются ризосферные микробы, подавляющие патогенную микрофлору. Они за короткие сроки способны формировать большую биомассу и не имеют общих вредителей и возбудителей болезней с томатом. Кроме того, на измельченных и запаханных растительных остатках активно развиваются микроорганизмы-целлюлозоразрушители. Они также способны к подавлению патогенной микрофло- ры. Целлюлозоразрушители поглощают большие дозы азота, что требует при их запашке дополнительно вносить в почву азотные удобрения. Эффект от использования злаковых культур проявляется постепенно, в течение ряда лет, и этот прием должен стать обязательным в технологии выращивания томата в весенних теплицах. Постепенно отпадает потребность в проведении химической защиты от трахеомикозов.

Монокультура в сочетании с высокими дозами балластных удобрений и поливной воды ухудшает не только микробиологический состав почвогрунтов. Параллельно происходит прогрессирующее падение почвенного плодородия, ухудшаются водно-физические свойства почвогрунтов. И если введение в оборот промежуточных сидеральных культур и разрыхлителей (опилки, шелуха риса, лузга подсолнечника, торф) в какой-то степени решает вопрос с плотностью и порозностью почв, то с высокой минерализацией возникает много проблем. Очень часто это усугубляется использованием минерализованной поливной воды. Такие почвогрунты нуждаются во внесении высоких доз органических удобрений, которые стали дефицитом изза сокращения поголовья КРС. Для снижения минерализации на карбонатных почвах с высоким $\mathrm{pH}$ необходимо применять в качестве фитомелиоранта фосфогипс с заделкой его в почву и проведением последующего ее увлажнения. Потребуется и изменение системы удобрений. Балластные удобрения можно вносить только с осени под фрезерование в дозах $\mathrm{N}_{120} \mathrm{P}_{120} \mathrm{~K}_{120}$, а через систему капельного орошения и в листовые подкормки должны вноситься только комплексные водорастворимые безбалластные удобрения с микроэлементами. Лучше выбирать удобрения с подкисляющим эффек- том. Общая доза удобрений, марки этих удобрений должны корректироваться по фазам роста и развития растений, состоянию самих растений и особенностям микроклимата. В ранневесенний период при недостатке освещенности соотношение азота к калию должно составлять $1: 2$, а при улучшении освещенности и усилении ростовых процессов изменяться до 1,5:2 или 1:1. При наступлении бутонизации, в период цветения и завязывания плодов увеличивается общая доза удобрений до 1,5- 2,5 г на растение и соотношение между азотом, фосфором и калием должно составлять 1:1:1. В период налива плодов опять должно быть увеличено внесение калия, а азот должен быть в амидной форме. В период налива плодов обязательны листовые подкормки. Особенно важны листовые подкормки при поливе минерализованной водой. Через систему капельного орошения в этом случае лучше вносить мочевину, поскольку она как органическое удобрение не увеличивает концентрацию раствора.

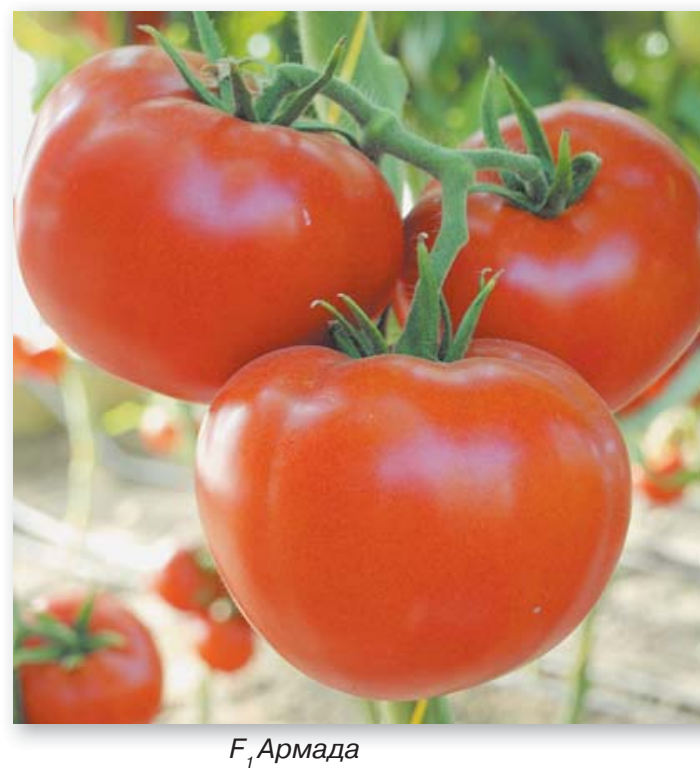


с применением химических фунгицидов только при эпифитотийном развитии заболеваний позволяет в большинстве случаев получать экологически безопасную продукцию.

Наличие генетической устойчивости ко многим грибным болезням, реализуемое в создании сортов с комплексной устойчивостью, позволяет практически полностью отказаться от использования химических препаратов. Для борьбы с вирусными болезнями также наиболее перспективен путь создания устойчивых сортов, и предупреждение распространения патогенов с семенами, растительными остатками и через насекомых-переносчиков.

Для подавления вспышек столбура больше подходят карантинные и профилактические меры борьбы: уничтожение сорной растительности и переносчиков на прилегающей к теплицам территории. Химические меры борьбы здесь практически неэффективны.

Для разработки мер борьбы с вредными организмами необходимо проведение фитомониторинга, который позволяет определить для каждого объекта свой комплекс вредителей и возбудителей болезней, выбрать профилактические, карантинные, агротехнические и биологические меры борьбы с ними. При этом задействование всего комплекса защитных мер позволяет резко ограничить применение химических средств защиты растений или полностью отказаться от них. Только все планируемые мероприятия в комплексе дают нужный эффект.

Сортимент томата для весенних теплиц достаточно разнообразен и постоянно обновляется. В процессе селекции важное внимание уделяется созданию гибридов с комплексной устойчивостью к болезням. Это связано с недостаточно эффективной работой многих биопрепаратов против возбудителей болезней и постоянной эволюцией патогена с появлением новых, более вирулентных рас и штаммов. Существуют разные методы оценки устойчивости создаваемых гибридов к патогенам: от непосредственной оценки растений при искусственном заражении или в условиях эпифитотии, до генетического маркирования. Однако успех в этом деле возможен только при наличии генов устойчивости в популяции возделываемых томатов или их дикорастущих сородичей. Методы биотехнологии стали активно использоваться в селекции на устойчивость, но, как показывает практика, не всегда наличие гена устойчивости при генетическом маркировании подтверждает устойчивость материала в полевых условиях. Очень большое значение имеет собственный иммунитет растений, поддержание оптимального микроклимата и почвенного плодородия с исключением провоцирующих факторов, а также наличие морфологических признаков, снижающих риск свободного проникновения патогенов в растение. По таким возбудителям болезней, как томатная мозаика, табачная мозаика, бронзовость, желтая курчавость листьев, фузариозное и вертициллезное увядание, фузариозная гниль корневой шейки, кладоспориоз, мучнистая роса и ряд других, имеются гены устойчивости и создаваемые гибриды томата могут обладать этими генами, то есть будут иметь комплексную устойчивость к нескольким болезням одновременно. Однако в конкретных условиях при отсутствии той или иной болезни нет необходимости иметь гибрид со всеми возмож-

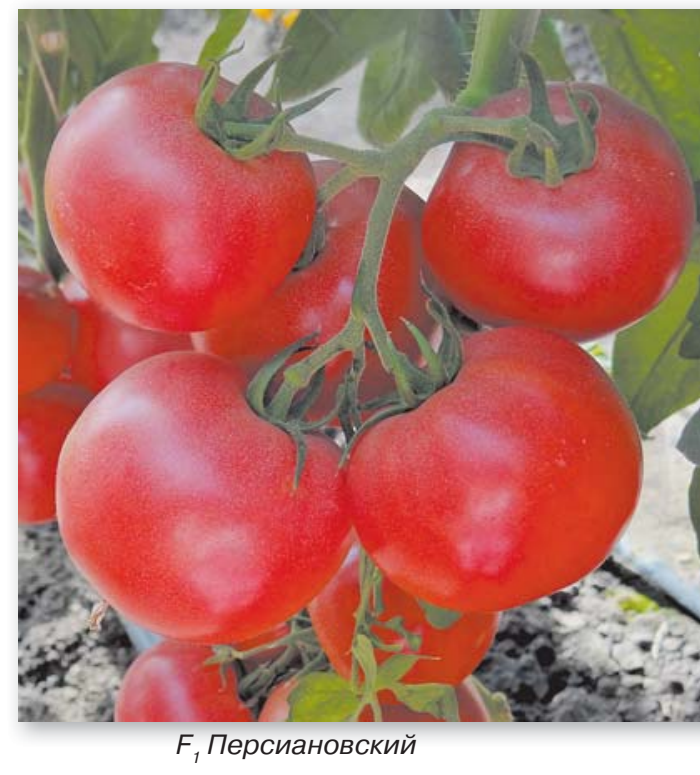

ными генами устойчивости. Тем более, что ряд особо опасных болезней не имеют генетической устойчивости в современном сортименте томатов. К числу последних относятся столбур, серая гниль, фитофтороз, многие бактериозы. Здесь наиболее эффективны биопрепараты в сочетании с карантинными, профилактическими и агротехническими мерами. Среди созданных нами гибридов томата высокой устойчивостью к комплексу болезней в условиях весенних теплиц отличаются гибриды $F_{1}$ Розанна, $F_{1}$ Армада, $F_{1}$ Бобрин, $F_{1}$ Пегас, $F_{1}$ Персиановский, $F_{1}$ Розовый носик, $F_{1}$ Бемби.

\section{Выводы}

Таким образом, при возделывании томата в весенних теплицах на юге России для получения экологически безопасной продукции необходимо:

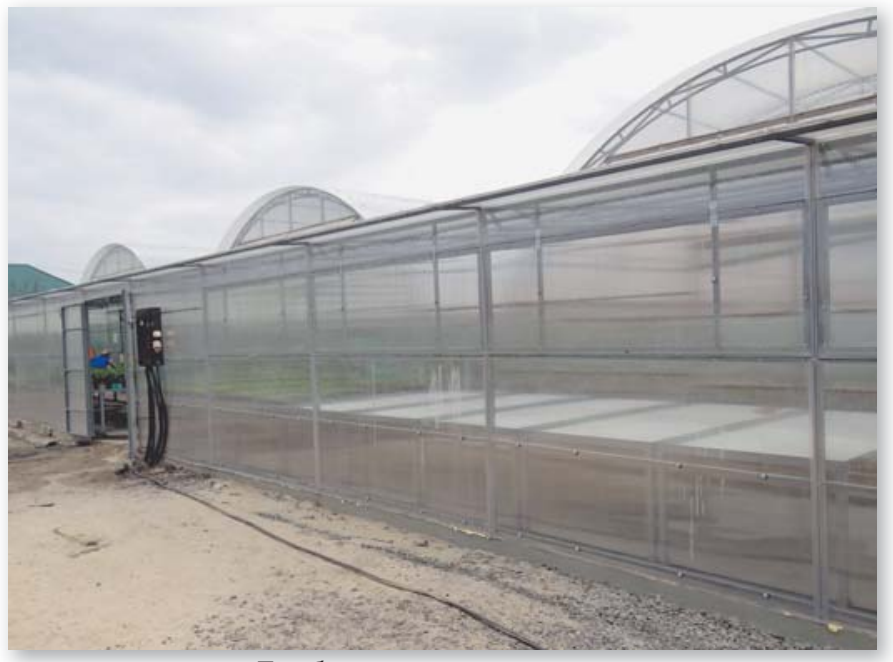

Тамбур при входе в теплицу

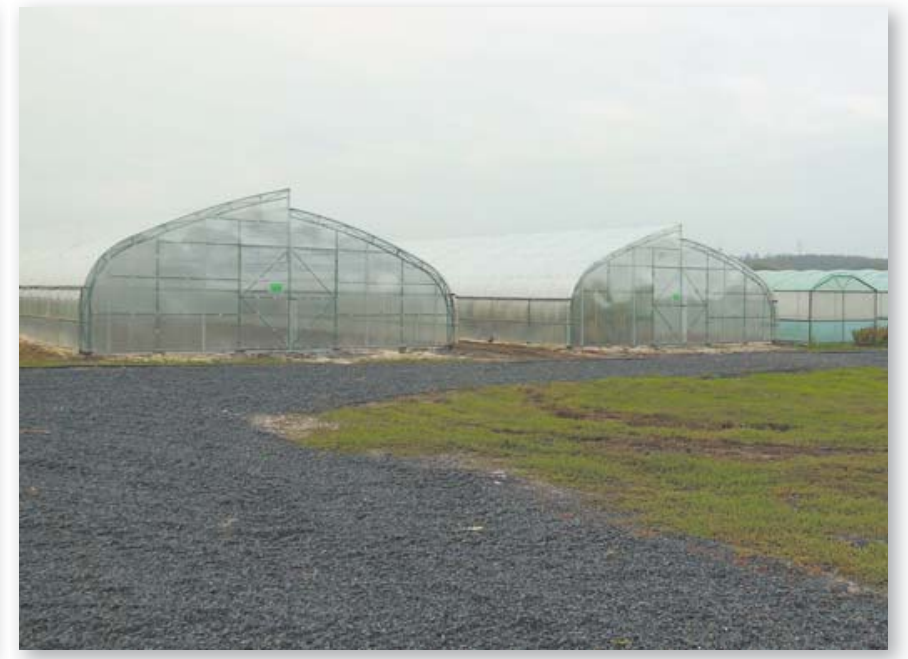

Теплицы с вытяжной вентиляцией 
- модернизировать теплицы, оснастив их вытяжной вентиляцией в верхней части кровли, противомоскитными сетками на всех вентиляционных системах, тамбурами с дезинфекционными барьерами на входе;

- должен быть увеличен внутренний объем теплиц за счет повышения их высоты до 4,5-4,7 м;

- в технологии выращивания томата в монокультуре на грунтах предусмотреть использование посева промежуточных культур на сидераты овса, тритикале или ржи;

- осуществить переход от применения балластных удобрений к использованию комплексных безбалластных с микроэлементами или специальных марок удобрений с микроэлементами, стимуляторами и регуляторами роста в привязке к конкретным фазам роста и развития растений, особенностям микроклимата и состояния растений;

- распределить дозу удобрений между основным внесением, корневыми и листовыми подкормками в пользу подкормок, увеличив их кратность;

- заменить чередование поливов и корневых подкормок только на подкормочные поливы растворами удобрений, снизив их концентрацию до 0,3-0,5\% и увеличить кратность листовых калийных подкормок при использовании минерализованной поливной воды;

- проводить размещение растений, их подвязку и формировку в соответствии с сортовыми особенностями, не допуская самозагущения и ухудшения освещенности и провет- риваемости посадок;

- по результатам фитомониторинга выявить наиболее опасных вредителей и возбудителей болезней и разработать систему мер защиты от них, включив в нее в качестве основных карантинные и профилактические мероприятия, агротехнические и биологические меры борьбы; предусмотреть преимущественное использование биопрепаратов с заменой химических средств защиты на малотоксичные с низкими нормами расхода;

- подобрать сортимент томата с комплексной устойчивостью к вредным организмам, сосредоточив усилия на применении специальных мер защиты против патогенов, не имеющих генетического контроля устойчивости.

\section{Библиографический список}

1.Литвинов С.С., Нурметов Р.Д. Защищенный грунт: стратегия развития // Картофель и овощи. 2013. №10. С. 10-11.

2.Гиш Р.А. Овощеводство защищенного грунта. Краснодар: ИП Профатилов, 2018. 464 с.

3.Редичкина Т., Артемьева Г. Модный розовый // Вестник овощевода. 2019. №9. С. 6-8.

4.Артемьева Г., Редичкина Т. Томат глазами аналитика // Вестник овощевода. 2015. №9. С. 7-9.

5.Редичкина Т. Особенности кривянского томата // Вестник овощевода. 2019. №3. С. 10-12.

6.Огнев В.В., Корсунов Е.И. Подвязка и формировка томата в весенних теплицах // Картофель и овощи. 2019. №7. С. 13-15.

7.Берников Н.И., Огнев В.В. Современное состояние и пути решения проблем развития овощного комплекса Ростовской области / Инновационные пути развития АПК: проблемы, и перспективы. Материалы международной научно-практической конференции. Персиановский, 2013. Т. 2. С. 98-101.

8.Огнев В.В., Терешонкова Т.А., Чернова Т.В., Прохорова К.Г. Селекция томата для пленочных теплиц: состояние и перспективы // Картофель и овощи. 2015. №11. С. 36-38.

9.Чернова Т.В., Огнев В.В., Корсунов Е.И. Томаты на юге России // Картофель и овощи. 2019. №11. С. 20-23.

10.Огнев В.В. Технология выращивания томата в весенних пленочных теплицах // Картофель и овощи. 2013. №1. С. 9-11.

11.Литвинов С.С. Методика полевого опыта в овощеводстве. М.: Россельхозакадемия, 2011. 649 с.

12.Технология управления численностью вредных организмов овощных культур тепличных агроценозов на основе интеграции методов и средств защиты растений. Методические рекомендации. М.: ФГБНУ «Росинформагротех», 2011. С. 86-87.

\section{Об авторах}

Чернова Татьяна Викторовна, селекционер, ССЦ «Ростовский» Агрохолдинг «Поиск»

Огнев Валерий Владимирович (ответственный за переписку), канд. с.-х. наук, доцент, директор ССЦ «Ростовский» Агрохолдинг «Поиск». E-mail: ognevvv@bk.ru

Авдеенко Светлана Сергеевна, канд. с.-х. наук, доцент, Донской государственный аграрный университет

Габибова Елена Николаевна, канд. с.-х. наук, доцент, Донской государственный аграрный университет

Корсунов Евгений Иванович, аспирант, Донской государственный аграрный университет

\section{References}

1.Litvinov S.S., Nurmetov R.D. Protected ground: development strategy. Potato and vegetables. 2013. No.10. Pp. 10-11 (In Russ.). 2.Gish R.A. Vegetable breeding of protected soil. Krasnodar: IB Profatilov. 2018. 464 p. (In Russ.).

3.Redichkina T., Artemyeva G. Fashion pink. Herald of vegetable grower. 2019. No.9. Pp. 6-8 (In Russ.).

4.Artemyeva G., Redickkina T. Tomato through the eyes of an analyst. Herald of vegetable grower. 2015.No.9. P. 7-9 (In Russ.).

5. Redichkina T. Features a tomato in Krivyanskaya village. Herald of vegetable grower. 2019. No.3. Pp. 10-12 (In Russ.).

6.Ognev V.V., Korsunov E.I. Garter and tomato formation in spring greenhouses Potato and vegetables. 2019. No.7. Pp. 13-15 (In Russ.).

7.Bernikov N.I., Ognev V.V. Modern state and ways to solve the problems of the development of the vegetable complex of the Rostov region. Sat. Innovative ways of development of the AIC: problems, and prospects. 2013. Vol. 2. Pp. 98-101(In Russ.).

8.Ognev V.V., Terejonkova T.A., Chernova T.V., Prokhorova K.G. Tomato selection for film greenhouses: state and prospects. Potato and vegetables. 2015. No.11. Pp. 36-38 (In Russ.).

9.Chernova T.V., Ognev V.V., Korsunov E.I. Tomatoes in southern Russia. Potato and vegetables. 2019. No.11. Pp. 20-23 (In Russ.).

10.Ognev V.V. The technology of growing tomatoes in spring film greenhouses. Potato and vegetables. 2013. No.1. Pp. 9-11 (In Russ.).

11. Litvinov S.S. Method of field experience in vegetable production. M.: Rosselkhozakademia. 2011. 649 p. (In Russ.).

12. Technology to manage the number of pests of vegetable crops of greenhouse agrocenoses on the basis of the integration of methods and means of plant protection. Methodical recommendations. M.: FGBNU Rosinformagrotech. 2011. Pp. 86-87 (In Russ.).

\section{Author details}

Chernova T.V., breeder, Rostovsky breeding centre of Poisk Agro holding

Ognev V.V. (corresponding author), Cand. Sci. (Agr.), associate professor, director of Rostovsky breeding centre of Poisk Agro holding. E-mail: ognevvv@bk.ru

Avdeenko S.S., Cand. Sci. (Agr.), associate professor, Donskoy State Agrarian University

Gabibova E.N., Cand. Sci. (Agr.), associate professor, Donskoy State Agrarian University

Korsunov E.I., postgraduate student, Donskoy State Agrarian University 